\title{
A Review of the Synthesis and Photoluminescence Properties of Hybrid ZnO and Carbon Nanomaterials
}

\author{
Protima Rauwel, ${ }^{1}$ Martin Salumaa, ${ }^{1}$ Andres Aasna, ${ }^{1}$ \\ Augustinas Galeckas, ${ }^{2}$ and Erwan Rauwel ${ }^{1}$ \\ ${ }^{1}$ Tartu College, Tallinn University of Technology, Puiestee 78, 51008 Tartu, Estonia \\ ${ }^{2}$ Department of Physics, University of Oslo, P.O. Box 1048, Blindern, 0316 Oslo, Norway
}

Correspondence should be addressed to Protima Rauwel; protima.rauwel@ttu.ee

Received 8 July 2016; Accepted 29 August 2016

Academic Editor: Stefano Bellucci

Copyright (C) 2016 Protima Rauwel et al. This is an open access article distributed under the Creative Commons Attribution License, which permits unrestricted use, distribution, and reproduction in any medium, provided the original work is properly cited.

Photoluminescent $\mathrm{ZnO}$ carbon nanomaterials are an emerging class of nanomaterials with unique optical properties. They each, $\mathrm{ZnO}$ and carbon nanomaterials, have an advantage of being nontoxic and environmentally friendly. Their cost-effective production methods along with simple synthesis routes are also of interest. Moreover, $\mathrm{ZnO}$ presents photoluminescence emission in the UV and visible region depending on the synthesis routes, shape, size, deep level, and surface defects. When combined with carbon nanomaterials, modification of surface defects in $\mathrm{ZnO}$ allows tuning of these photoluminescence properties to produce, for example, white light. Moreover, efficient energy transfer from the $\mathrm{ZnO}$ to carbon nanostructures makes them suitable candidates not only in energy harvesting applications but also in biosensors, photodetectors, and low temperature thermal imaging. This work reviews the synthesis and photoluminescence properties of 3 carbon allotropes: carbon quantum or nanodots, graphene, and carbon nanotubes when hybridized with $\mathrm{ZnO}$ nanostructures. Various synthesis routes for the hybrid materials with different morphologies of $\mathrm{ZnO}$ are presented. Moreover, differences in photoluminescence emission when combining $\mathrm{ZnO}$ with each of the three different allotropes are analysed.

\section{Introduction}

$\mathrm{ZnO}$ has been one of the most studied materials for over two decades. Being a semiconductor material with a band gap of $3.37 \mathrm{eV}$, it luminesces in the blue and ultraviolet region of the visible spectrum. $\mathrm{ZnO}$ is an attractive material due to easy accessibility of raw materials, low production costs, and its nontoxicity properties. On the other hand, $\mathrm{ZnO}$ has a superior advantage in nanotechnology as it is easy to synthesize as nanostructures $[1,2]$. During the last decade, many reports have been published on the synthesis of $\mathrm{ZnO}$ nanoparticles [3], nanoflakes [4], hexagonal prismatic rods [5], nanoflowers [6], nanorods [7], nanopillars, or nanosheets using multiple methods of synthesis [8]. These studies have shown that the morphology of $\mathrm{ZnO}$ also plays a very important role in determining the physical properties of the material. Presently, the modification of the optoelectronic properties is the current area of focus and one of these methods includes doping with rare earths as well as cationic or anionic substitutions $[9,10]$.
However, the optical properties also vary as a function of the morphology. Furthermore, the optical properties of bulk $\mathrm{ZnO}$ can be modified by nanostructuring via the increase of native (intrinsic) defects in the crystalline structure or via size reduction generating in turn a substantial increase of the surface to volume ratio, thereby producing a stronger surface defect related emission. For example, rose like $\mathrm{ZnO}$ exhibits an enhancement in fluorescence properties [11]. Rhombus shaped $\mathrm{ZnO}$ nanostructures applied to dye sensitized solar cell have manifested an enhancement in the short circuit current [12]. A recent study has also shown that $\mathrm{ZnO}$ nanoparticles can exhibit interesting optical properties with appropriate choice of precursors [13], therefore justifying that, by engineering $\mathrm{O}$ and $\mathrm{Zn}$ vacancies, it is possible to vary the photoluminescence emission of $\mathrm{ZnO}$. However, the large band gap of $\mathrm{ZnO}$ limits its use as a UV light photocatalyst as only $5 \%$ of sunlight is captured by $\mathrm{ZnO}$. So, shifting the optical response to the visible range should increase its photocatalytic efficiencies. These methods include doping with metal, 
nonmetals, and the synthesis of heterostructures [14, 15]. However, $\mathrm{ZnO}$ nanoparticles or quantum dots on their own may not serve very well for electron transport mainly due to two reasons: firstly there may not be sufficient contact between the particles themselves and secondly even if there is contact between them, the formation of grain boundaries would hinder electron transport and deteriorate possible device fabrication. However, due to its intrinsic properties and abundance, $\mathrm{ZnO}$ is nevertheless widely investigated for large-scale activities such as purifying water and air $[8,16]$.

Another means to enhance the photoluminescent properties involves the hybridization of the material with carbon based nanomaterials such as carbon nanotubes (CNT), carbon quantum dots (CQDs), or graphene among the carbon allotropes [17, 18]. In fact, carbon based structures such as fullerenes, graphene, CNT, and CQDs have been investigated for the enhancement of performances of photodetectors and photovoltaic devices [19-23]. In recent years, carbon based nanostructures have sparked tremendous research interest due to their superior chemical, physical, mechanical, and electronic properties [24]. Since they are abundant and have been successfully shown to be biocompatible, they have been integrated into bioimaging, medical diagnosis, catalysis, and optoelectronic applications [25-28].

Among the various carbon allotropes, CQD or carbon nanodots have emerged as a rising candidate for many applications. Due to their high quantum yield [29], low cytotoxicity [30], high photostability [31], and nonblinking character [32] they are seen as potential candidates for applications in photovoltaics, photocatalysis [33], and light emitting diodes [34]. The significantly large amount of $\pi$ electrons moreover makes them viable for hot carrier solar cells [35]. Yu et al. have recently demonstrated that grapheneCQDs have this potential contrary to CNT-CQD or $\mathrm{TiO}_{2}-$ CQDs where charge transfer in the latter two was absent [36].

Graphene on the other hand has shown enormous potential in the fabrication of solar cells. In one instance, graphene is used as a charge conducting layer in a solar cell device [37]. Some other studies have reported that graphene can be used as an electrode for dye-sensitized and organic solar cells [38-41]. Similarly, carbon nanotubes (CNT) or cylindrical fullerenes have interesting optical properties because their excitation gives rise to strongly bound excitons [42]. CNT are classified into single-wall carbon nanotube (SWCNT) and multiwall carbon nanotube (MWCNT). SWCNT finds applications in the electronic industry considering their high electron mobility and also in biomolecule sensors [43]. SWCNT have also been studied as a possible solar cell material [44]. Additionally, MWCNT find applications as counterelectrodes in dye sensitized solar cells $[45,46]$.

This review article aims at bringing together various $\mathrm{ZnO}$-nanocarbon hybrid materials. Three major allotropes of carbon nanomaterials, namely, CNT, graphene, and CQD hybridizing with nano- $\mathrm{ZnO}$, are analysed. This work also evaluates and compares the photoluminescence properties of these hybrid materials in terms of their defects and morphologies determined by various growth techniques which are also reviewed and assessed.

\section{Synthesis and Morphological Characterization of ZnO Carbon Based Nanostructures}

2.1. $\mathrm{ZnO}-\mathrm{CQD}$ Synthesis. $\mathrm{ZnO}-\mathrm{CQD}$ nanohybrids have been prepared by various groups. Yu et al. have used hydrothermal synthesis by introducing $\mathrm{Zn}$ (Acetate) $)_{2}, 2 \mathrm{H}_{2} \mathrm{O}(0.25 \mathrm{M})$ in an alcoholic solution containing CQD for $8 \mathrm{H}$ at $100^{\circ} \mathrm{C}$ [47]. The resulting nanohybrids shown in Figure 1 are indeed $\mathrm{ZnO}$ CQD nanocomposite with the CQD encapsulating the $\mathrm{ZnO}$ nanoparticle. Different morphologies of $\mathrm{ZnO}$ nanoparticles have been combined with CQD. Zhang et al. have used electrospinning hydrothermal synthesis and have obtained $\mathrm{ZnO}$ nanoflowers. They subsequently dispersed these $\mathrm{ZnO}$ nanoflowers in a solution containing CQD. The nanohybrid material was then dried at $80^{\circ} \mathrm{C}$ [48]. In their study, the CQDs were themselves prepared via a green synthesis route using sucrose. On the other hand, the $\mathrm{ZnO}$ nanoflowers were prepared via electrospinning of zinc acetate dehydrated at $470^{\circ} \mathrm{C}$ followed by hydrothermal synthesis of the $\mathrm{Zn}$ nanospheres using a solution of zinc nitrate hexahydrate and hexamethylenetetramine at $95^{\circ} \mathrm{C}$. The nanocomposite was subsequently synthesized by dispersing CQD dots in water along with different concentrations of $\mathrm{ZnO}$ nanoflowers.

Another green synthesis approach consists of using Dfructose and $\mathrm{NaOH}$. The nanocomposite was then prepared by hydrothermal synthesis of $\mathrm{Zn}\left(\mathrm{CH}_{3} \mathrm{COO}\right)_{2} \cdot 2 \mathrm{H}_{2} \mathrm{O}$ in the presence of $\mathrm{CQD}$ at $80^{\circ} \mathrm{C}$ [49]. Other approaches of combining $\mathrm{ZnO}$ and $\mathrm{CQD}$ using sol-gel methods also exist. $\mathrm{ZnO}$ mesoporous films have been studied by Suzuki et al. but contrary to the above-mentioned studies the CQDs were synthesized by less environmentally friendly methods such as Arginine. $\mathrm{HCl}$ and 1,2-ethylendiamine. The solution for $\mathrm{ZnO}$ was produced using $\mathrm{Zn}\left(\mathrm{CH}_{3} \mathrm{COO}\right)_{2} \cdot 2 \mathrm{H}_{2} \mathrm{O} / \mathrm{EtOH} / \mathrm{H}_{2} \mathrm{O} / \mathrm{Zonyl}$ and then mixed with various concentrations of CQD [50]. The morphology of the hybrid nanocomposite consisted of agglomerated nanocrystals of $\mathrm{ZnO}$ blended with CQDs.

Other methods to grow CQD comprise reacting graphite with $\mathrm{HSO}_{4}$ for a longer period of 6 days and subsequently combining them with $\mathrm{ZnO}$ prepared by sol-gel methods using $\mathrm{Zn}\left(\mathrm{NO}_{3}\right)_{2} \cdot 6 \mathrm{H}_{2} \mathrm{O}$ [51]. Muthulingam et al. have used $\mathrm{N}$ doped $\mathrm{ZnO}$ via low temperature hydrothermal synthesis at $60^{\circ} \mathrm{C}$. The CQDs were isolated by combining carbon black ink $\mathrm{H}_{2} \mathrm{SO}_{4}$ and $\mathrm{HNO}_{3}$ at $240^{\circ} \mathrm{C}$ for 2 hours [52]. Pyrolysis has also been used by $\mathrm{Ma}$ et al. for the synthesis of these nanocomposites which consisted of hydrothermal synthesis of $\mathrm{ZnO}$ and pyrolysis of a metal organic framework as precursor. Here, oxybisbenzoic acid, zinc nitrate hexahydrate, $4,4^{\prime}$-bipyridine, and N,N-dimethylformamide were combined [53]. Currently, porous materials are regarded as attractive materials for photocatalytic activity due to their large surface areas. Very recently, Ding et al. have combined $\mathrm{ZnO}$ foam with CQD [54]. In their work, they synthesized the $\mathrm{ZnO}$ foam with a one-step combustion method where $\mathrm{Zn}\left(\mathrm{NO}_{3}\right)_{2} \cdot 6 \mathrm{H}_{2} \mathrm{O}$ was dissolved into ethylene glycol monomethyl ether and burnt at $120^{\circ} \mathrm{C}$. They also obtained CQD via a green hydrothermal synthesis route using sucrose. The nanocomposite was then formed by dispersing the $\mathrm{ZnO}$ foam into the CQD solution. 

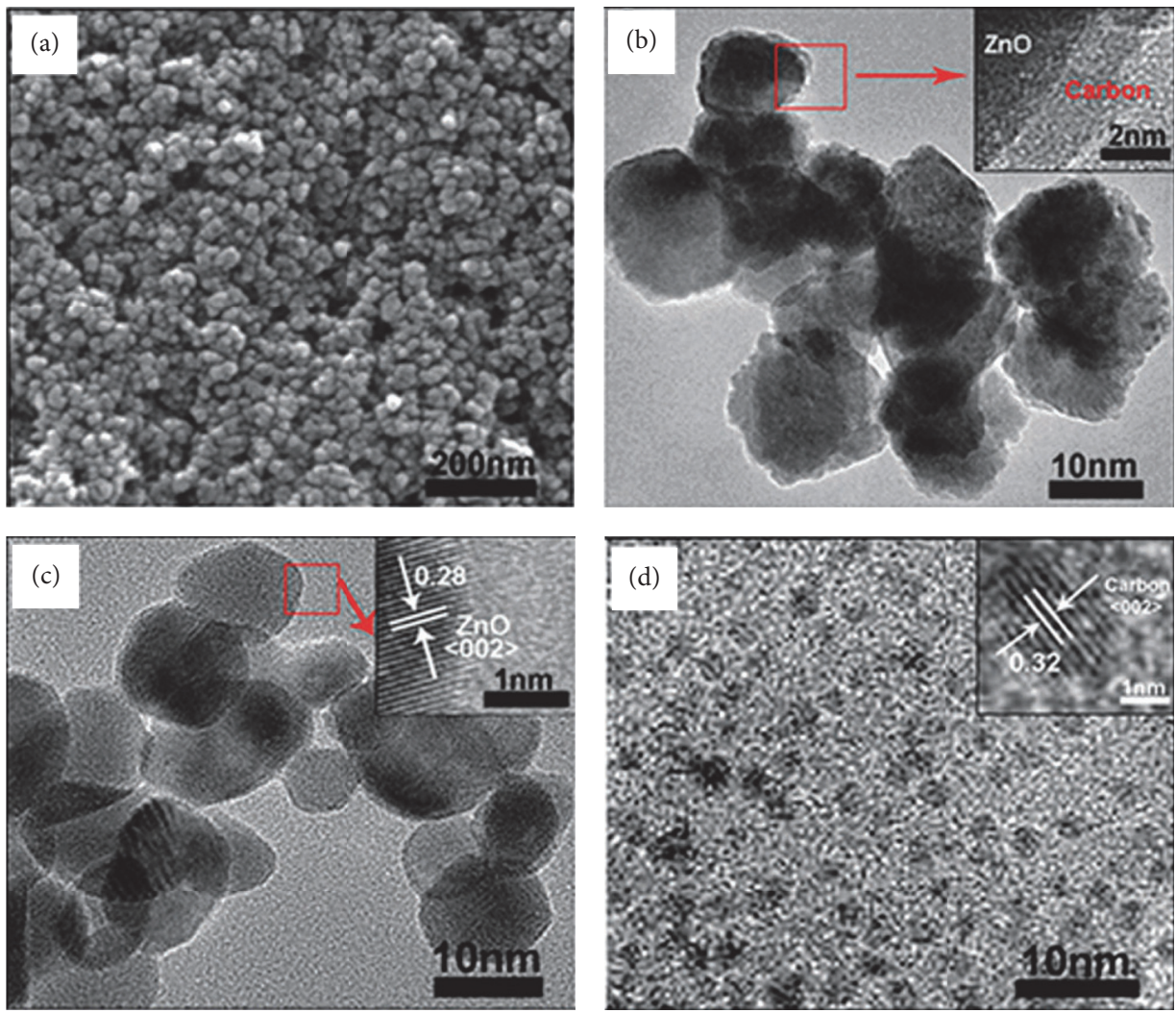

FIGURE 1: (a) SEM and (b) TEM images of the nanohybrid material (c) and (d) TEM images of pure ZnO and pure CQD, respectively (partially reproduced from [46], copyright licence number: 3940681292519).

2.2. $\mathrm{ZnO}$-Graphene Synthesis. For the synthesis of reduced graphene oxide ( $\mathrm{rGO}$ ) $\mathrm{ZnO}$ nanocomposites, the first step involves the reduction of the graphene oxide (GO) with hydrazine also known as one-step reduction process. When followed by thermal annealing on a quartz substrate, it is known as a two-step reduction process [55]. The difference in the morphology of the reduced graphene oxide (rGO) via a one-step or two-step process is mostly depicted in the roughness of the films where a two-step reduction process produces a smoother surface with a few cracks and folds $[56,57]$. Other than reducing graphene oxide, graphene can be produced by other methods described in this section. The synthesis of $\mathrm{ZnO}$-graphene composites is very well studied in the literature. Synthesis techniques as simple as ultrasonication of $\mathrm{ZnO}$ with $\mathrm{rGO}$ are available [58]. Liu et al. have used microwave assisted synthesis [59] where commercial graphite was first oxidized via Hummers' method [60]. GO suspension was added to $\mathrm{ZnSO}_{4}$ and sonicated to homogenise the solution. $\mathrm{NaOH}$ was further added to increase the $\mathrm{pH}$ to 9 and was subject to microwaves. The $\mathrm{pH}$ of 9 was found to be optimal for the precipitation of $\mathrm{ZnO}$.

Additionally, different morphologies of $\mathrm{ZnO}$ have been used to fabricate $\mathrm{ZnO}$-graphene nanocomposites. Yin et al. have used electrochemical deposition of $\mathrm{ZnO}$ nanorods on the rGO where the conductivity of the rGO determined the growth rate of $\mathrm{ZnO}$ nanorods. In effect, the conductivity of graphene is instrumental in producing hydroxyl ions which promote the growth of $\mathrm{ZnO}$ rods [57]. CVD growth of graphene on $\mathrm{Ni}$ and $\mathrm{Cu}$ substrates is also commonly practised. Dong et al. have obtained $\mathrm{ZnO}$ nanorod-graphene nanocomposite via hydrothermal synthesis of $\mathrm{ZnCl}_{2}$ at $120^{\circ} \mathrm{C}$ [61]. Yi et al. have used hydrophilic plasma-etched $\mathrm{ZnO}$ nanorods that were subsequently dispersed in a solution containing distilled water and CVD grown graphene [62]. Other $\mathrm{ZnO}$-graphene nanocomposites have also been synthesized where $\mathrm{ZnO}$ either was deposited by CVD [63] or was hydrothermally grown as nanorods [64, 65] onto GO obtained via Hummers method. Sol-gel methods have been used to grow $\mathrm{ZnO}$ nanoparticles that were subsequently spin coated onto graphene and thermally annealed [66]. The spin coating and annealing were performed twice before the substrate with $\mathrm{ZnO}$ seeds on the surface was dipped into zinc nitrate hexahydrate and hexamethylenetetramine at $90^{\circ} \mathrm{C}$ for 90 min thereby producing nanorods.

Flower shaped $\mathrm{ZnO}$-graphene nanocomposites have also been prepared by various groups. $\mathrm{Xu}$ et al. have reduced $\mathrm{GO}$ with hydrazine and hydrothermally synthesized $\mathrm{ZnO}$ nanoflowers in the presence of graphene [67]. Hummers' method to prepare graphene followed by hydrothermal synthesis of $\mathrm{ZnO}$ nanoflowers has also been conducted by various groups [68]. CVD growth of graphene followed by electrochemical deposition of $\mathrm{ZnO}$ nanoflowers has also been carried out [69]. 
2.3. CNT-ZnO Synthesis. Carbon nanotubes and $\mathrm{ZnO}$ nanocomposites have been prepared by various techniques. In the literature, reports of $\mathrm{CNT}-\mathrm{ZnO}$ hybrids prepared by ball milling are available [70]. Zhang et al. deposited $\mathrm{ZnO}$ nanodots onto the CNT films by ultrasonic spray for applications as electrodes [71]. 3D structures of $\mathrm{ZnO} \mathrm{CNT}$ have also been grown by many groups [72]. Chemical precipitation of $\mathrm{ZnO}$ on SWCNT was carried out by Paul et al. [73]. Pulsed laser deposited (PLD) ZnO on MWCNT was synthesized via a hydrothermal method by Saleh et al. [74, 75]. A large majority of the synthesis techniques use a functionalizing agent to prepare the CNT for decoration. The acid treatment debundles the nanotubes and disposes functional groups on their sidewalls which serve as anchorage points for the $\mathrm{ZnO}$ nanoparticles. Aziz et al. have dispersed CNT in sodium dodecyl sulphate followed by ball milling the $\mathrm{ZnO}$ that was previously obtained by hydrothermal synthesis [76]. CNT have also been grown by spray pyrolysis methods and purified thereafter to get rid of the iron impurities; they were then sintered at $700^{\circ} \mathrm{C}$ with $\mathrm{ZnO}$ prepared by oxidizing $\mathrm{Zn}$ dust at very high temperatures under oxygen rich conditions [77]. Another type of $\mathrm{ZnO}$-CNT hybrid structure has been synthesized via Atomic Layer Deposition (ALD). Here coating of $\mathrm{ZnO}$ is applied to the outer wall and also to the inner walls of the CNT. Depending upon the inert or functional groups present on the CNT, the morphology of the $\mathrm{ZnO}$ coating can be varied. Li et al. have obtained a smooth conformal coating of $\mathrm{ZnO}$ on vertically aligned CNT using diethyl zinc and water as $\mathrm{Zn}$ and $\mathrm{O}$ sources, respectively [78]. Kim et al. have obtained nanoparticle like $\mathrm{ZnO}$ coating on the CNT giving a rough appearance to the nanohybrid material [79].

\section{Photoluminescence of ZnO Carbon Based Structures}

3.1. Photoluminescence of $\mathrm{ZnO}$ Nanoparticles. $\mathrm{ZnO}$ on its own luminesces in the visible and UV regions. In the visible region the emission is attributed to intrinsic defects induced during the synthesis itself. The UV emission is due to excitonic recombination $[80,81]$. Various luminescence emissions in the visible region are possible depending upon the synthesis procedure, morphology, vacancies, and surface defects [82]. Rauwel et al. have studied the influence of hydrate precursor in nonaqueous sol-gel methods and have shown that the PL emission can be tuned by using the appropriate precursor (Figure 2) [13]. Moreover, they have also shown that the embedment of $\mathrm{ZnO}$ nanoparticles in a metal oxide matrix produces differences in the PL response due to the passivation of the surface defects [83]. Various colored emissions have been obtained for $\mathrm{ZnO}$ : orange [84], blue [85], green, and red [86].

\subsection{Photoluminescence of $\mathrm{ZnO}$ and Nanocarbon Hybrid Materials}

3.2.1. $\mathrm{ZnO}$-Graphene Nanohybrids. Combining $\mathrm{ZnO}$ with graphene has produced various photoluminescence emissions. Blue and red emissions have been observed in graphene

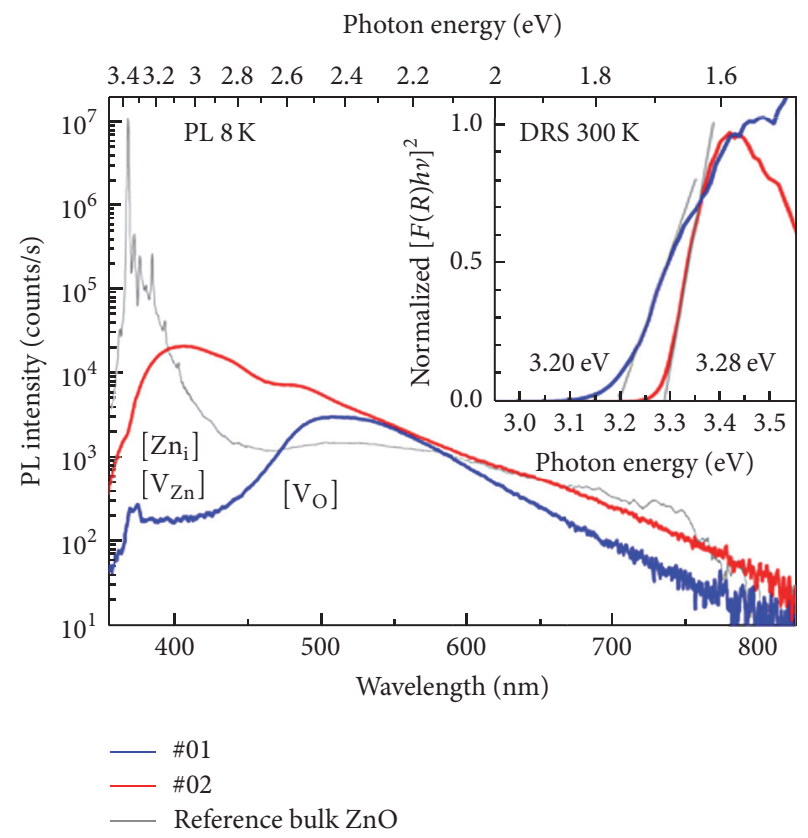

Figure 2: PL spectra at $8 \mathrm{~K}$ from $\mathrm{ZnO}$ nanoparticles produced using zinc acetylacetonate hydrate (curve \#01, type-A NPs) and zinc acetate (curve \#02, type-B NPs) along with the reference spectrum of bulk $\mathrm{ZnO}$ (grey curve). Inset shows optical band edges of the corresponding nanoparticles estimated from the diffuse-reflectance spectra (DRS) at $300 \mathrm{~K}$ (reproduced with permission from [13]).

alone [87, 88]. Khenfouch et al. [89] have succeeded in obtaining white light emission from $\mathrm{ZnO}$ nanorod hybridized with few layers of graphene as shown in Figure 3. At room temperature (RT) excitation of $280 \mathrm{~nm}$ in the deep UV, they have observed several PL emission wavelengths and have been able to attribute them to various defects. For example, the green luminescence at $524 \mathrm{~nm}$ has been attributed to radiative recombination of simple ionized oxygen vacancies. This is very commonly observed in oxygen deficient $\mathrm{ZnO}$ [13]. The yellow-orange luminescence is typical of sol-gel or hydrothermal methods [90]. They have attributed the emissions at $482 \mathrm{~nm}$ and $498 \mathrm{~nm}$ to isolated $\mathrm{sp}^{2}$ clusters within the carbon-oxygen $\mathrm{sp}^{3}$ matrix. Moreover, poor dispersion or aggregation of graphene flakes gives rise to emissions at $684 \mathrm{~nm}$ and $686 \mathrm{~nm}$. Kwon et al. have illustrated an increase in the PL intensity corresponding to the free exciton transition (FEE) at $375 \mathrm{~nm}$ with increase in GO concentration in their sample. Biroju et al. have grown vertically aligned $\mathrm{ZnO}$ on graphene and have compared the PL emission before and after annealing the hybrid material [91]. They noticed a significant improvement in the UV and visible PL on annealing. The reduction in the green and yellow emissions was attributed to the reduction in deep level defects $\mathrm{O}_{\mathrm{zn}}$ or neutral $\mathrm{O}_{i}$. The yellow emission was attributed to a reduction in ionized $\mathrm{O}_{\mathrm{i}}$.

Band gap tuning of graphene- $\mathrm{ZnO}$ hybrid structures was studied by Singh et al. [92]. They observed not only a blue shift in their photoluminescence emission but also a quenching effect on increasing the rGO concentration. They attribute 


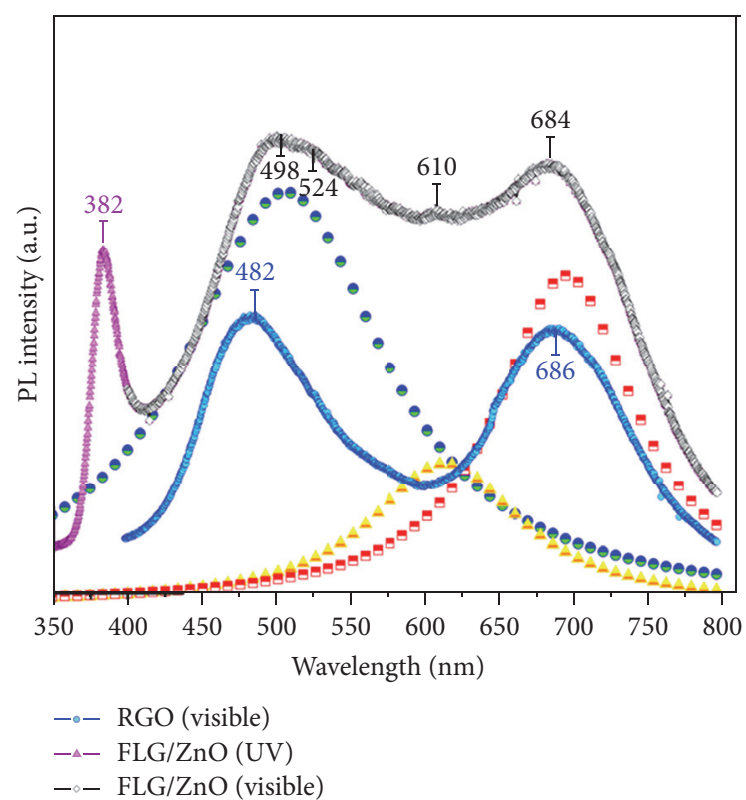

FIGURE 3: White light emission from CQD-ZnO hybrid structures Khenfouch et al. (reproduced from [89] copyright licence number: 3940721191296).

both phenomena to a depletion region being formed at the interface of the nanocomposite arising due to the p-type conductivity of $\mathrm{ZnO}$ and n-type conductivity of graphene. In fact, a green light emitting diode has been fabricated by $\mathrm{Wu}$ et al. [93], where they combine $\mathrm{ZnO}$ nanowires and graphene. Under forward bias conditions at $6 \mathrm{~V}$ they observe a green emission and a reduced UV emission. Here, the injected holes from graphene combine with electrons located in defects in $\mathrm{ZnO}$. Since a nanowire has a large surface to volume ratio, implying that the majority of defects are on the surface, this suggests that the interface between graphene and $\mathrm{ZnO}$ plays an important role in the emission properties of the material. Quenching of emission from surface states of $\mathrm{ZnO}$ by passivating it with a layer of $\mathrm{rGO}$ has also been studied by Han et al. [94-96]. Nevertheless, the contrary was observed for the UV emission which was enhanced owing to the increase in $\mathrm{sp}^{2}$ carbon. This phenomenon is further reinforced by Lee et al. who used nonoxidized graphene with $\mathrm{ZnO}$ and studied their photoluminescent properties [97]. Their study provides fundamental understanding of the effect of oxygen filling effect of graphene when hybridized with $\mathrm{ZnO}$. The FEE was decreased for $\mathrm{ZnO}$ nonoxidized graphene samples on increasing the nonoxidized graphene proportion. They also observed a deep level emission at $530 \mathrm{eV}$ which was attributed to interband transitions from $\mathrm{Zn}$ interstitials to $\mathrm{O}$ vacancies. Another possible effect was also the excitonic recombination from the conduction band to oxygen defect band gap state. However, for the GO- $\mathrm{ZnO}$, the effect on FEE emission was the opposite. Moreover, other than the formation of a p-n junction another possible explanation to the blue shift was a reduction in oxygen defects when combined with GO which was also translated by a reduction of the green visible luminescence. Furthermore indirect excitation of zinc, commonly termed as sensitization or "antenna" effect [98], has also been observed when combining $\mathrm{ZnO}$ with graphene. In fact, Han et al. have observed an increase in the PL luminescence coming from the hybrid material due to an antenna effect, compared to $\mathrm{ZnO}$ alone. They attribute it to the resonant excitation of graphene plasmon and their conversion into photons that propagate to the conjugated $\mathrm{ZnO}$ surface $[94,99]$.

3.2.2. $\mathrm{ZnO}-\mathrm{CQD}$ Nanohybrids. Carbon quantum dots or graphene quantum dots emanate a wide range of luminescence in the visible region depending upon their size and surface defects. Moreover, their photoluminescence emission varies as a function of the excitation wavelength [100-102]. In the PL spectra presented in Figure 4(a), a blue shift is observed when excited with higher wavelengths [103]. This also indicates that the CQD can be excited with visible wavelengths. As presented above, nanosized $\mathrm{ZnO}$ presents a defect related emission in the blue-green part of the visible spectrum. Such a hybrid structure therefore becomes a good candidate for white light emission [104]. Overlapping of energy bands of the two materials has been successful in producing a charge transfer between them when the hybrid material is excited in the visible or UV regions $[47,104]$.

In Figure 4(b) a significant peak at $550 \mathrm{~nm}$ corresponding to deep level defects in $\mathrm{ZnO}$ is visible along with its band edge emission at $375 \mathrm{~nm}$. However, the emission intensities of $\mathrm{ZnO}-\mathrm{CQD}$ hybrid show a heightened intensity implying energetic interactions in such systems. It also shows quenching in the defect related emission when the ratio of $\mathrm{ZnO}: \mathrm{C}$ is at $4: 1$. Suzuki et al. [105] have explained that the quenching of the FEE as a function of CQD increase in the sample could be attributed to the internal absorption with higher CQD concentration. In their samples, they also present orange luminescence at $1.85 \mathrm{eV}$ emanating from deep level defects $\mathrm{O}_{\mathrm{zn}}$ or neutral $\mathrm{O}_{\mathrm{i}}$ and it is a result of their synthesis route. They also observe a blue shift in the defect level emission from $1.8 \mathrm{eV}$ to $2.2 \mathrm{eV}$ with increase in CQD concentration. This implies that the oxygen interstitial related defects no longer emit the orange luminescence and the contributions were mostly from surface defects of $\mathrm{ZnO}$ and CQD as indicated by the green luminescence. This also implies that the addition of CQD increases the oxygen vacancies in $\mathrm{ZnO}$ by the reduction reaction. In a previous work, $\mathrm{He}$ et al. have explained the quenching of luminescence with increase in CQD by the lack of dispersion and formation of CQD aggregates which reduces contact between $\mathrm{ZnO}$ and CQD thereby quenching the PL spectrum [104]. The mechanisms for the various colored emissions in the visible region are provided in Figure 5. Moreover, they also observed white light emission for intermediate concentrations of CQD along with a nonlinear increase in CQD/ZnO PL ratio with the incorporation of CQD. Such a nonlinear interaction is indicative of excitation transfer through dipole interactions. Using the energy level structure of $\mathrm{N}$ doped CQD of Tang et al. [106], they have compared the band gap of $\mathrm{ZnO}$ to the HOMO-LUMO states in CQD and have suggested a charge transfer from conduction band of $\mathrm{ZnO}$ to the $\mathrm{O} \pi^{*}$ LUMO of CQD via dipole resonance mechanisms. 


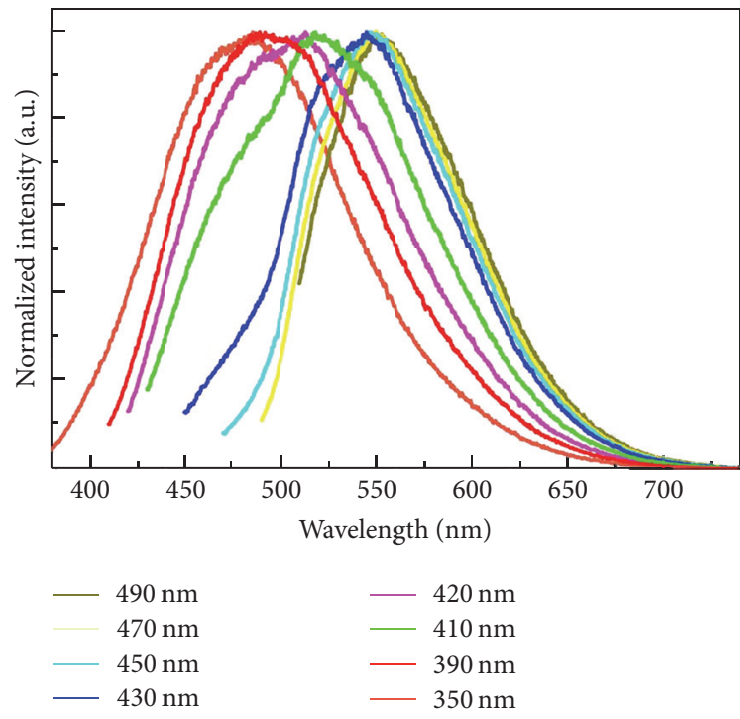

(a)

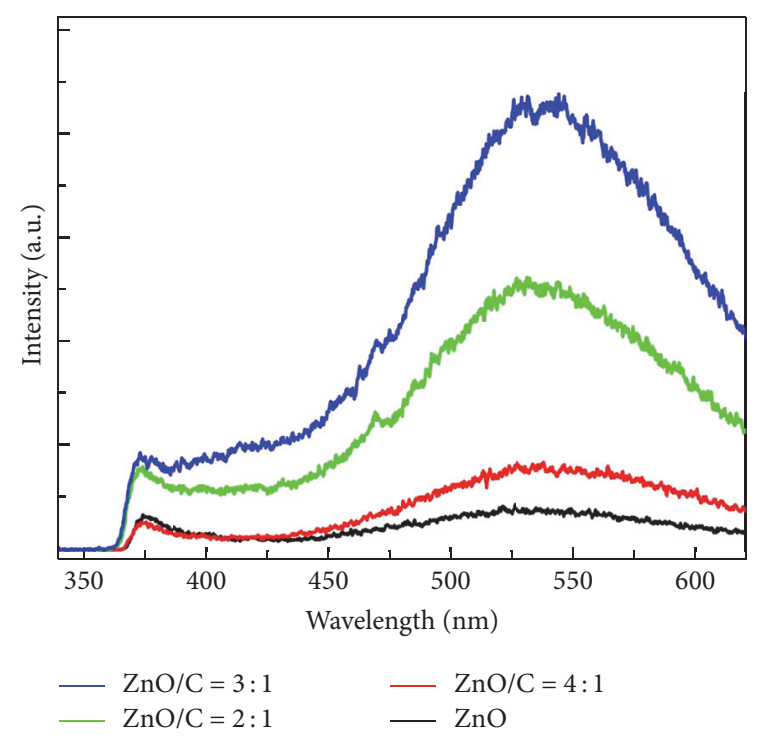

(b)

FIgUre 4: (a) Photoluminescence emissions from CQD when excited at different wavelengths. (b) PL emission spectra of ZnO-CQD with different $\mathrm{ZnO}$ : CQD proportions (reproduced from [103] under Creative Free Commons).

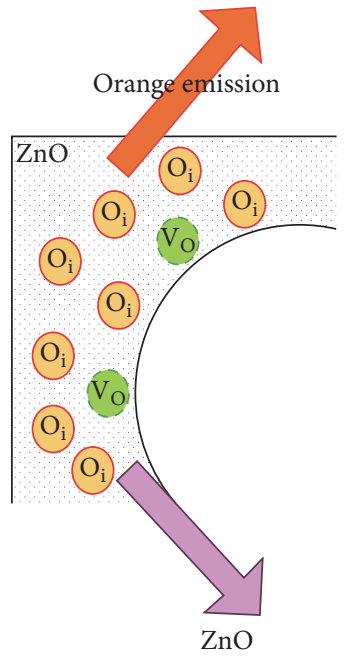

Bare $\mathrm{ZnO}$

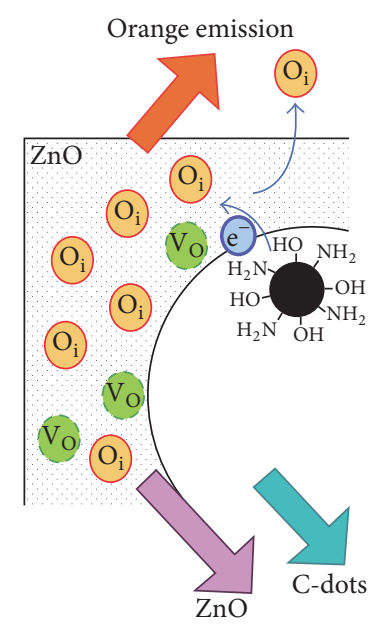

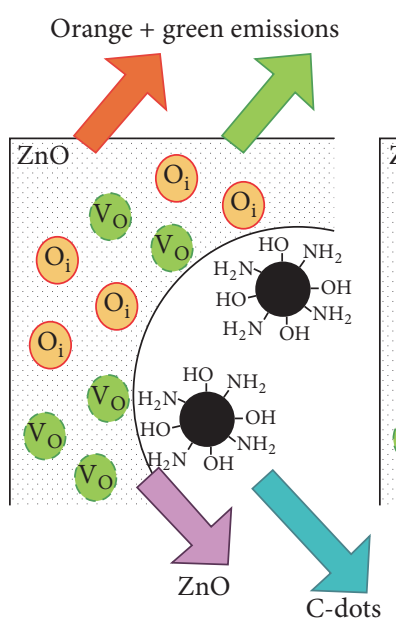

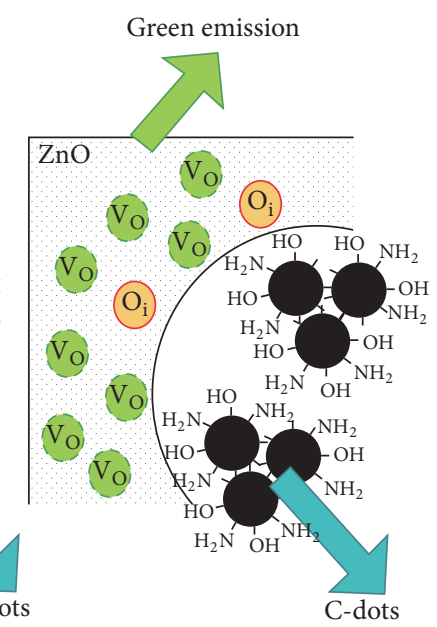

Near-edge band of $\mathrm{ZnO}$ and $\mathrm{C}$-dot emissions
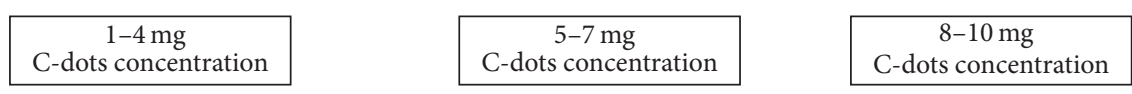

FIgURE 5: Defect related deep level emissions and various visible colored luminescent emissions as a function of CQD concentration (reproduced from [105], with copyright licence number: 3940691218874).

3.2.3. $\mathrm{ZnO}-\mathrm{CNT}$ Nanohybrids. There have been several theoretical and experimental studies related to the defect related luminescent properties enhancement of CNT-ZnO structure $[107,108]$. Depending on the method of the $\mathrm{ZnO}$ grown with regard to the defects present [109], determined also by its morphology, namely, flower, rod, and dots, the characteristic green emission of $\mathrm{ZnO}$ is either intensified or quenched. For example, Gupta et al. noticed enhancement of the photoluminescence emission in their hybrid structure at $510 \mathrm{~nm}$ compared to $\mathrm{ZnO}$ alone [77]. This enhancement was explained by enhancement of oxygen vacancy related defects at the interface of $\mathrm{ZnO}-\mathrm{CNT}$. Considering the large surface to volume ratio, the green emission becomes dominant. On the other hand, in lily-like- $\mathrm{ZnO}$, a broad yellow-green emission (ionized oxygen vacancy, oxygen vacancy, or $\mathrm{Zn}$ interstitial) band along with a strong near band edge emission is indicative of a high quality $\mathrm{ZnO}$ sample [110]. When combined with $\mathrm{ZnO}$, the red shift of the FEE band was attributed to excitonic recombination in shallow traps or surface states created on hybridizing. Moreover, quenching of 


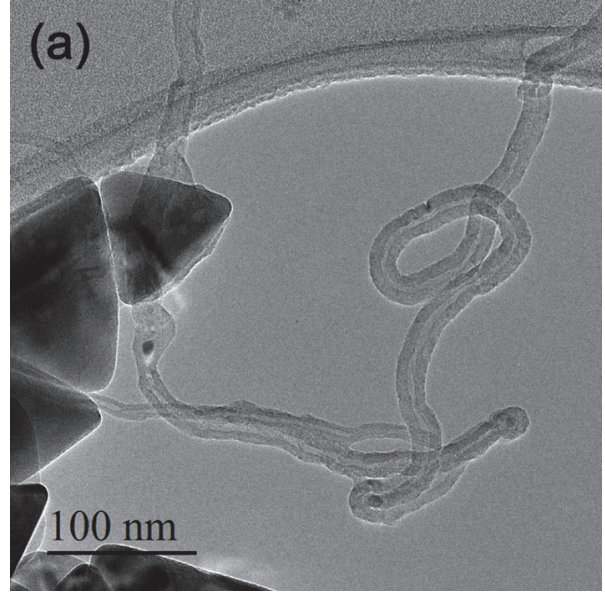

(a)

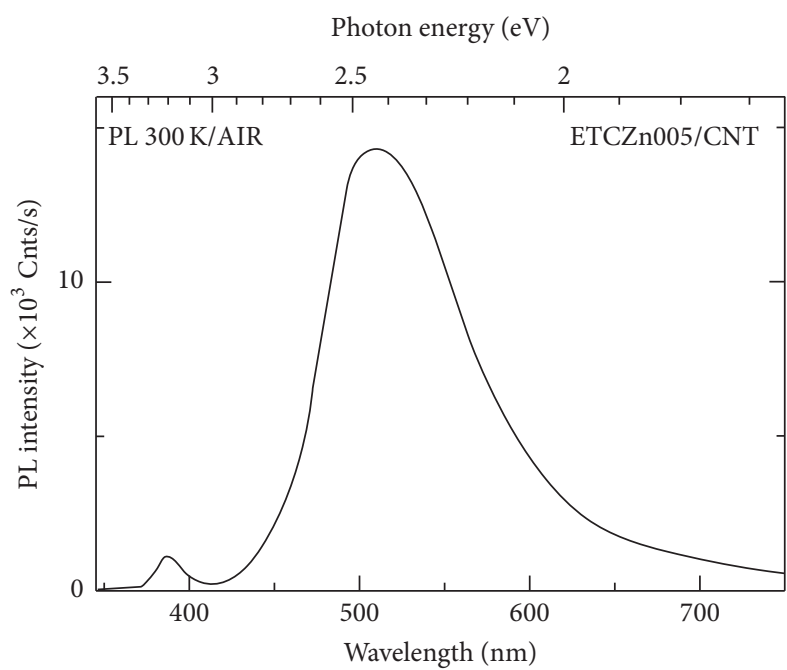

(b)

Figure 6: (a) TEM image of $\mathrm{ZnO}$ nanoparticles synthesized using zinc acetate at $300^{\circ} \mathrm{C}$ in the presence of CNT and (b) PL spectra at RT.

the visible luminescence or filling of defects when combined with CNT along with a transfer of photoexcited charges from $\mathrm{ZnO}$ to CNT empty states has also been reported. Stability of these hybrid structures is also of importance as studied by Zhu et al. [111]. They studied $\mathrm{ZnO}$ nanoparticles with a high density of stacking faults hybridized to CNT on growth and after 24 days. In both cases their PL spectra were identical indicating the stability of these structures. They both consisted of emissions at $376 \mathrm{~nm}$ and $490 \mathrm{~nm}$. After annealing, the peak at $490 \mathrm{~nm}$ became more intense and blue shifted to $485 \mathrm{~nm}$ indicating that new defects such as $\mathrm{O}$ and $\mathrm{Zn}$ (peak at $632 \mathrm{~nm}$ ) vacancies were formed through a probable conversion of stacking faults into oxygen vacancies. All of the above were studied under band gap excitation. In general, each peak has its significance and a band edge emission intensity helps identify the crystalline quality of $\mathrm{ZnO}$ used. Yellow-green emission corresponds to a recombination of a photogenerated hole and an ionized oxygen vacancy [112]. The FEE emission enhancement not only is a function of crystallinity but is also enhanced by the surface plasmon emission effects of CNT [113]. Moreover ZnO-CNT systems exhibit charge transfer from $\mathrm{ZnO}$ to $\mathrm{CNT}$ manifested by enhanced quenching of the luminescence and very short lifetime as compared to bulk $\mathrm{ZnO}$ alone [114] as determined by time resolved PL. In order to better understand all the phenomena that occur at the interface between $\mathrm{ZnO}$ NPs and CNT, theoretical calculations have been performed by Chai et al. to model the charge transfer from $\mathrm{ZnO}$ to metallic CNT [115]. More recently, ZnO carbon based nanohybrids have been synthesized by nonaqueous sol-gel method. One observes that $\mathrm{ZnO}$ nanoparticles with sharp edges are directly connected to the CNT network (Figure 6(a)). The direct synthesis of $\mathrm{ZnO}$ nanoparticles in the presence of CNT and their bonding to CNT promote the green emission usually exhibited by oxygen vacancies (Figure 6(b)). The complete result of these investigations will be published in a forthcoming paper and cannot be discussed in this review.

\section{Conclusions}

The technological advancement in the synthesis and characterization of metal oxide nanomaterials is a rapidly growing field. Zinc oxide is a very versatile optical material having a relatively wide range of UV absorption and demonstrating photostability. Moreover, being nontoxic therefore makes it biocompatible. $\mathrm{ZnO}$ nanomaterials can be synthesized via a broad range of chemical of physical methods that enable obtaining different morphologies. Defect engineering or surface modification by choosing appropriate synthesis techniques is a way of tailoring the photoluminescence properties of the material that has been demonstrated in numerous reports. $\mathrm{ZnO}$ has already been exploited by industry, with applications in photocatalysis or in sunscreens which are solar filters that block all ultraviolet radiations.

The interest in $\mathrm{ZnO}$ has not only grown but, with the advent of the abundant and ecofriendly carbon based nanomaterials, hybrid $\mathrm{ZnO}$ carbon based materials have aroused the curiosity of several researchers. This work has focused on the three widely used carbon based materials that combine with $\mathrm{ZnO}$ nanoparticle: graphene, $\mathrm{CNT}$, and carbon quantum dots. However the synthesis of $\mathrm{ZnO}$ hybrid for each carbon based material is different. The synthesis is a minimum 2- or 3-step procedure with synthesizing the carbon nanomaterial as a first step. The second step consists usually of growing the $\mathrm{ZnO}$ nanomaterial and the third step involves combining them. Sometimes a fourth step such as postsynthesis annealing is necessary when passivating defects. A two-step method reduces the number of steps by growing the $\mathrm{ZnO}$ directly on the carbon based material as a second step.

CNT are usually grown by CVD methods on metal catalyst nanoparticles such as Ni. Furthermore, as-grown CNT contain a large number of impurities. Treating the CNT with acid or heat has a twofold advantage: firstly, it gets rid of the residual impurities in the as-grown sample 
and secondly it creates functional groups on the side wall of the CNT which facilitate their decoration with various nanoparticles. A more environmentally friendly technique to purify the CNT is sonication. $\mathrm{ZnO}$ can also be directly grown via, for example, an Atomic Layer Deposition (ALD) coating on CNT, among other techniques. CQD used in $\mathrm{ZnO}-\mathrm{CQD}$ hybrid materials, on the other hand, can be synthesized by green synthesis routes, for instance, by reacting $\mathrm{D}$-fructose with $\mathrm{NaOH}$ or via sucrose. Green synthesis routes have been developed as a more economical and valuable alternative for the large-scale production of metal nanoparticles to avoid the use of the generation of hazardous substances and can be based on the utilization of plant extracts or molecules produced by plants that may act as both reducing and capping agents, for example. Less ecofriendly techniques by acid treating graphite are also used in the production of CQD. In graphene- $\mathrm{ZnO}$ hybrid material, $\mathrm{rGO}$ is obtained from graphene oxide in one or two steps. GO is usually reduced via hydrazine and could be followed by a thermal treatment. GO is usually obtained from Hummers' method. CVD grown graphene on $\mathrm{Ni}$ and $\mathrm{Cu}$ is also used in the hybrid mix. Other techniques combine the carbon nanomaterial with $\mathrm{ZnO}$ with the latter having been prepared by spray pyrolysis, ball milling, hydrothermal synthesis, or spin coating.

These hybrid materials present photoluminescence properties which vary as a function of the carbon based materials used. In fact, the emission from $\mathrm{ZnO}$, either UV or visible, can be engineered by passivating or generating defects at the interface of the hybrid materials, considering their large surface to volume ratios. Characteristic emissions from these materials such as red, blue, green, yellow, and orange can therefore be enhanced or quenched. In some cases white light emission has also been obtained. Moreover, charge transfer in these materials due to overlapping bands in the excited state makes them highly suitable for photocurrent generation and next generation of solar cells, including flexible, transparent photovoltaics. Carbon and $\mathrm{ZnO}$ are ecofriendly, biodegradable, and omnipresent. Even though more ecofriendly synthesis routes exist for the carbon based materials, nonetheless, very few reports where the former are applied to the synthesis of hybrid ZnO-carbon based nanomaterials, are available. For example, presently, acid treatments of CNT and graphite and the use of hydrazine which are all very toxic are of common usage. Nevertheless, being of very high potential in various optoelectronic applications, new and green routes for their synthesis are the need of the hour.

\section{Competing Interests}

The authors declare that there is no conflict of interests regarding the publication of this paper.

\section{Acknowledgments}

The authors wish to acknowledge the Estonian Research Council (Grant PUT431), the European Regional Development Fund Project TK134 (TAR16019), MENESR, MAEDI French Ministries (Parrot Program no. 33787YJ), and the Norwegian Research Council. The NAMUR Project of the
European Regional Development Funds is acknowledged for access to the FEI Titan G2 80-200.

\section{References}

[1] X.-Y. Liu, C.-X. Shan, C. Jiao, S.-P. Wang, H.-F. Zhao, and D.$\mathrm{Z}$. Shen, "Pure ultraviolet emission from $\mathrm{ZnO}$ nanowire-based p-n heterostructures," Optics Letters, vol. 39, no. 3, pp. 422-425, 2014.

[2] N. Gogurla, A. K. Sinha, S. Santra, S. Manna, and S. K. Ray, "Multifunctional Au-ZnO plasmonic nanostructures for enhanced UV photodetector and room temperature NO sensing devices," Scientific Reports, vol. 4, article 6483, 2014.

[3] R. Jalal, E. K. Goharshadi, M. Abareshi, M. Moosavi, A. Yousefi, and P. Nancarrow, "ZnO nanofluids: green synthesis, characterization, and antibacterial activity," Materials Chemistry and Physics, vol. 121, no. 1-2, pp. 198-201, 2010.

[4] A. Singh and P. Kumar, "Structural, morphological and optical properties of sol gel processed $\mathrm{CdZnO}$ nanostructured films: effect of precursor solvents," International Nano Letters, vol. 3, article 57, 2013.

[5] A. Stanković, S. Dimitrijević, and D. Uskoković, "Influence of size scale and morphology on antibacterial properties of $\mathrm{ZnO}$ powders hydrothemally synthesized using different surface stabilizing agents," Colloids and Surfaces B: Biointerfaces, vol. 102, pp. 21-28, 2013.

[6] N. Talebian, S. M. Amininezhad, and M. Doudi, "Controllable synthesis of $\mathrm{ZnO}$ nanoparticles and their morphologydependent antibacterial and optical properties," Journal of Photochemistry and Photobiology B: Biology, vol. 120, pp. 66-73, 2013.

[7] E. E. Hafez, H. Shokry Hassan, M. F. Elkady, and E. Salama, "Assessment of antibacterial activity for synthesized zinc oxide nanorods against plant pathogenic strains," International Journal of Scientific \& Technology Research, vol. 3, no. 9, pp. 318-324, 2014.

[8] A. Kołodziejczak-Radzimska and T. Jesionowski, "Zinc oxidefrom synthesis to application: a review," Materials, vol. 7, no. 4, pp. 2833-2881, 2014.

[9] S. Major, A. Banerjee, and K. L. Chopra, "Optical and electronic properties of zinc oxide films prepared by spray pyrolysis," Thin Solid Films, vol. 125, no. 1-2, pp. 179-185, 1985.

[10] J. Hu and R. G. Gordon, “Textured fluorine-doped ZnO films by atmospheric pressure chemical vapor deposition and their use in amorphous silicon solar cells," Solar Cells, vol. 30, no. 1-4, pp. 437-450, 1991.

[11] Y. Gong, C. Zou, Y. Yao et al., "A facile approach to synthesize rose-like $\mathrm{ZnO} /$ reduced graphene oxide composite: fluorescence and photocatalytic properties," Journal of Materials Science, vol. 49, no. 16, pp. 5658-5666, 2014.

[12] Y. Zhu, F. Deng, L. Feng, H. Ding, S. Ismat Shah, and C. Ni, "Hierarchical rhombus-shaped $\mathrm{ZnO}$ array: synthesis, formation mechanism and solar cell application," Journal of Alloys and Compounds, vol. 607, pp. 132-138, 2014.

[13] E. Rauwel, A. Galeckas, P. Rauwel, M. F. Sunding, and H. Fjellvaåg, "Precursor-dependent blue-green photoluminescence emission of $\mathrm{ZnO}$ nanoparticles," The Journal of Physical Chemistry C, vol. 115, no. 51, pp. 25227-25233, 2011.

[14] S. G. Kumar and K. S. R. K. Rao, "Zinc oxide based photocatalysis: tailoring surface-bulk structure and related interfacial charge carrier dynamics for better environmental applications," RSC Advances, vol. 5, no. 5, pp. 3306-3351, 2015. 
[15] F. Barka-Bouaifel, B. Sieber, N. Bezzi et al., "Synthesis and photocatalytic activity of iodine-doped $\mathrm{ZnO}$ nanoflowers," Journal of Materials Chemistry, vol. 21, no. 29, pp. 10982-10989, 2011.

[16] A. B. Djurišić, X. Chen, Y. H. Leung, and A. Man Ching $\mathrm{Ng}$, "ZnO nanostructures: growth, properties and applications," Journal of Materials Chemistry, vol. 22, no. 14, pp. 6526-6535, 2012.

[17] D. Eder, "Carbon nanotube-inorganic hybrids," Chemical Reviews, vol. 110, no. 3, pp. 1348-1385, 2010.

[18] P. Rauwel, A. Galeckas, M. Salumaa, F. Ducroquet, and E. Rauwel, "Revealing photocurrent generation in hybrid nanocomposite combining carbon nanotubes and $\mathrm{HfO} 2$ cubic phase nanoparticle," Beilstein Journal of Nanotechnology, vol. 7, pp. 1075-1085, 2016.

[19] S.-H. Cheng, T.-M. Weng, M.-L. Lu, W.-C. Tan, J.-Y. Chen, and Y.-F. Chen, "All carbon-based photodetectors: an eminent integration of graphite quantum dots and two dimensional graphene," Scientific Reports, vol. 3, article 2694, 2013.

[20] G. Konstantatos, M. Badioli, L. Gaudreau et al., "Hybrid graphene-quantum dot phototransistors with ultrahigh gain," Nature Nanotechnology, vol. 7, no. 6, pp. 363-368, 2012.

[21] K. Tvrdy, P. A. Frantsuzov, and P. V. Kamat, "Photoinduced electron transfer from semiconductor quantum dots to metal oxide nanoparticles," Proceedings of the National Academy of Sciences of the United States of America, vol. 108, no. 1, pp. 29-34, 2011.

[22] I. V. Lightcap and P. V. Kamat, "Fortification of CdSe quantum dots with graphene oxide. Excited state interactions and light energy conversion," Journal of the American Chemical Society, vol. 134, no. 16, pp. 7109-7116, 2012.

[23] W. Zhang, C.-P. Chuu, J.-K. Huang et al., "Ultrahigh-gain photodetectors based on atomically thin graphene- $\mathrm{MoS}_{2}$ heterostructures," Scientific Reports, vol. 4, article 3826, 2014.

[24] O. Kozák, M. Sudolská, G. Pramanik, P. Cígler, M. Otyepka, and R. Zbořil, "Photoluminescent Carbon Nanostructures," Chemistry of Materials, vol. 28, no. 12, pp. 4085-4128, 2016.

[25] W. U. Huynh, J. J. Dittmer, and A. P. Alivisatos, "Hybrid nanorod-polymer solar cells," Science, vol. 295, no. 5564, pp. 2425-2427, 2002.

[26] J. K. Jaiswal, E. R. Goldman, H. Mattoussi, and S. M. Simon, "Use of quantum dots for live cell imaging," Nature Methods, vol. 1, no. 1, pp. 73-78, 2004.

[27] Y. Li, Y. Hu, Y. Zhao et al., "An electrochemical avenue to greenluminescent graphene quantum dots as potential electronacceptors for photovoltaics," Advanced Materials, vol. 23, no. 6, pp. 776-780, 2011.

[28] V. Gupta, N. Chaudhary, R. Srivastava, G. D. Sharma, R. Bhardwaj, and S. Chand, "Luminscent graphene quantum dots for organic photovoltaic devices," Journal of the American Chemical Society, vol. 133, no. 26, pp. 9960-9963, 2011.

[29] S. Zhu, Q. Meng, L. Wang et al., "Highly photoluminescent carbon dots for multicolor patterning, sensors, and bioimaging," Angewandte Chemie-International Edition, vol. 52, no. 14, pp. 3953-3957, 2013.

[30] Q. Wang, X. Huang, Y. Long et al., "Hollow luminescent carbon dots for drug delivery," Carbon, vol. 59, pp. 192-199, 2013.

[31] L. Cao, X. Wang, M. J. Meziani et al., "Carbon dots for multiphoton bioimaging," Journal of the American Chemical Society, vol. 129, no. 37, pp. 11318-11319, 2007.

[32] Y.-P. Sun, B. Zhou, Y. Lin et al., "Quantum-sized carbon dots for bright and colorful photoluminescence," Journal of the
American Chemical Society, vol. 128, no. 24, pp. 7756-7757, 2006.

[33] H. Zhang, H. Huang, H. Ming et al., "Carbon quantum dots $/ \mathrm{Ag}_{3} \mathrm{PO}_{4}$ complex photocatalysts with enhanced photocatalytic activity and stability under visible light," Journal of Materials Chemistry, vol. 22, no. 21, pp. 10501-10506, 2012.

[34] F. Wang, Y.-H. Chen, C.-Y. Liu, and D.-G. Ma, "White lightemitting devices based on carbon dots' electroluminescence," Chemical Communications, vol. 47, no. 12, pp. 3502-3504, 2011.

[35] M. L. Mueller, X. Yan, B. Dragnea, and L.-S. Li, "Slow hot-carrier relaxation in colloidal graphene quantum dots," Nano Letters, vol. 11, no. 1, pp. 56-60, 2011.

[36] P. Yu, X. Wen, Y.-R. Toh et al., "Efficient electron transfer in carbon nanodot-graphene oxide nanocomposites," Journal of Materials Chemistry C, vol. 2, no. 16, pp. 2894-2901, 2014.

[37] Z. Liu, Q. Liu, Y. Huang et al., "Organic photovoltaic devices based on a novel acceptor material: graphene," Advanced Materials, vol. 20, no. 20, pp. 3924-3930, 2008.

[38] X. Wang, L. Zhi, and K. Müllen, "Transparent, conductive graphene electrodes for dye-sensitized solar cells," Nano Letters, vol. 8, no. 1, pp. 323-327, 2008.

[39] J. Wu, H. A. Becerril, Z. Bao, Z. Liu, Y. Chen, and P. Peumans, "Organic solar cells with solution-processed graphene transparent electrodes," Applied Physics Letters, vol. 92, no. 26, Article ID 263302, 2008.

[40] G. Eda, Y.-Y. Lin, S. Miller, C.-W. Chen, W.-F. Su, and M. Chhowalla, "Transparent and conducting electrodes for organic electronics from reduced graphene oxide," Applied Physics Letters, vol. 92, no. 23, Article ID 233305, 2008.

[41] X. Wang, L. Zhi, N. Tsao, Ž. Tomović, J. Li, and K. Müllen, "Transparent carbon films as electrodes in organic solar cells," Angewandte Chemie -International Edition, vol. 47, no. 16, pp. 2990-2992, 2008.

[42] P. Avouris, M. Freitag, and V. Perebeinos, "Carbon-nanotube photonics and optoelectronics," Nature Photonics, vol. 2, no. 6, pp. 341-350, 2008.

[43] A. Bianco and M. Prato, "Can carbon nanotubes be considered useful tools for biological applications?" Advanced Materials, vol. 15, no. 20, pp. 1765-1768, 2003.

[44] C. Klinger, Y. Patel, and H. W. C. Postma, "Carbon nanotube solar cells," PLoS ONE, vol. 7, no. 5, Article ID e37806, 2012.

[45] W. J. Lee, E. Ramasamy, D. Y. Lee, and J. S. Song, "Efficient dyesensitized solar cells with catalytic multiwall carbon nanotube counter electrodes," ACS Applied Materials \& Interfaces, vol. 1, no. 6, pp. 1145-1149, 2009.

[46] D. Benetti, K. T. Dembele, J. Benavides et al., "Functionalized multi-wall carbon nanotubes/ $\mathrm{TiO}_{2}$ composites as efficient photoanodes for dye sensitized solar cells," Journal of Materials Chemistry C, vol. 4, no. 16, pp. 3555-3562, 2016.

[47] H. Yu, H. Zhang, H. Huang et al., " $\mathrm{ZnO} /$ carbon quantum dots nanocomposites: one-step fabrication and superior photocatalytic ability for toxic gas degradation under visible light at room temperature," New Journal of Chemistry, vol. 36, no. 4, pp. 1031-1035, 2012.

[48] X. Zhang, J. Pan, C. Zhu et al., "The visible light catalytic properties of carbon quantum dots/ZnO nanoflowers composites," Journal of Materials Science: Materials in Electronics, vol. 26, no. 5, pp. 2861-2866, 2015.

[49] H. Bozetine, Q. Wang, A. Barras et al., "Green chemistry approach for the synthesis of $\mathrm{ZnO}$-carbon dots nanocomposites with good photocatalytic properties under visible light," Journal of Colloid and Interface Science, vol. 465, pp. 286-294, 2016. 
[50] K. Suzuki, L. Malfatti, D. Carboni et al., "Energy transfer induced by carbon quantum dots in porous zinc oxide nanocomposite films," The Journal of Physical Chemistry C, vol. 119, no. 5, pp. 2837-2843, 2015.

[51] Y. Li, B.-P. Zhang, J.-X. Zhao, Z.-H. Ge, X.-K. Zhao, and L. Zou, "ZnO/carbon quantum dots heterostructure with enhanced photocatalytic properties," Applied Surface Science, vol. 279, pp. 367-373, 2013.

[52] S. Muthulingam, I.-H. Lee, and P. Uthirakumar, "Highly efficient degradation of dyes by carbon quantum dots/N-doped zinc oxide (CQD/N-ZnO) photocatalyst and its compatibility on three different commercial dyes under daylight," Journal of Colloid and Interface Science, vol. 455, pp. 101-109, 2015.

[53] Q. Ma, Z. Zhang, and Z. Yu, "Synthesis of carbon quantum dots and zinc oxide nanosheets by pyrolysis of novel metal-organic framework compounds," Journal of Alloys and Compounds, vol. 642, pp. 148-152, 2015.

[54] D. Ding, W. Lan, Z. Yang et al., "A simple method for preparing $\mathrm{ZnO}$ foam/carbon quantum dots nanocomposite and their photocatalytic applications," Materials Science in Semiconductor Processing, vol. 47, pp. 25-31, 2016.

[55] X. Zhou, X. Huang, X. Qi et al., "In situ synthesis of metal nanoparticles on single-layer graphene oxide and reduced graphene oxide surfaces," The Journal of Physical Chemistry $C$, vol. 113, no. 25, pp. 10842-10846, 2009.

[56] D. K. L. Tsang, B. J. Marsden, S. L. Fok, and G. Hall, "Graphite thermal expansion relationship for different temperature ranges," Carbon, vol. 43, no. 14, pp. 2902-2906, 2005.

[57] Z. Yin, S. Wu, X. Zhou et al., "Electrochemical deposition of $\mathrm{ZnO}$ nanorods on transparent reduced graphene oxide electrodes for hybrid solar cells," Small, vol. 6, no. 2, pp. 307312, 2010.

[58] T. Xu, L. Zhang, H. Cheng, and Y. Zhu, "Significantly enhanced photocatalytic performance of $\mathrm{ZnO}$ via graphene hybridization and the mechanism study," Applied Catalysis B: Environmental, vol. 101, no. 3-4, pp. 382-387, 2011.

[59] X. Liu, L. Pan, T. Lv et al., "Microwave-assisted synthesis of $\mathrm{ZnO}$-graphene composite for photocatalytic reduction of Cr(vi)," Catalysis Science \& Technology, vol. 1, no. 7, pp. 11891193, 2011.

[60] H. Li, T. Lu, L. Pan, Y. Zhang, and Z. Sun, "Electrosorption behavior of graphene in $\mathrm{NaCl}$ solutions," Journal of Materials Chemistry, vol. 19, no. 37, pp. 6773-6779, 2009.

[61] X. Dong, Y. Cao, J. Wang et al., "Hybrid structure of zinc oxide nanorods and three dimensional graphene foam for supercapacitor and electrochemical sensor applications," RSC Advances, vol. 2, no. 10, pp. 4364-4369, 2012.

[62] J. Yi, J. M. Lee, and W. I. Park, "Vertically aligned ZnO nanorods and graphene hybrid architectures for high-sensitive flexible gas sensors," Sensors and Actuators B: Chemical, vol. 155, no. 1, pp. 264-269, 2011.

[63] C. Wu, F. Li, Y. Zhang, and T. Guo, "Improving the field emission of graphene by depositing zinc oxide nanorods on its surface," Carbon, vol. 50, no. 10, pp. 3622-3626, 2012.

[64] Z. Chen, N. Zhang, and Y.-J. Xu, "Synthesis of graphene$\mathrm{ZnO}$ nanorod nanocomposites with improved photoactivity and anti-photocorrosion," CrystEngComm, vol. 15, no. 15, pp. 3022-3030, 2013.

[65] A. R. Marlinda, N. M. Huang, M. R. Muhamad et al., "Highly efficient preparation of $\mathrm{ZnO}$ nanorods decorated reduced graphene oxide nanocomposites," Materials Letters, vol. 80, pp. 9-12, 2012.
[66] W. M. Choi, K.-S. Shin, H. S. Lee et al., "Selective growth of $\mathrm{ZnO}$ nanorods on $\mathrm{SiO}_{2} / \mathrm{Si}$ substrates using a graphene buffer layer," Nano Research, vol. 4, no. 5, pp. 440-447, 2011.

[67] S. Xu, L. Fu, T. S. H. Pham, A. Yu, F. Han, and L. Chen, "Preparation of $\mathrm{ZnO}$ flower/reduced graphene oxide composite with enhanced photocatalytic performance under sunlight," Ceramics International, vol. 41, no. 3, pp. 4007-4013, 2015.

[68] H. R. Pant, C. H. Park, P. Pokharel, L. D. Tijing, D. S. Lee, and C. S. Kim, "ZnO micro-flowers assembled on reduced graphene sheets with high photocatalytic activity for removal of pollutants," Powder Technology, vol. 235, pp. 853-858, 2013.

[69] N. S. A. Aziz, T. Nishiyama, N. I. Rusli, M. R. Mahmood, K. Yasui, and A. M. Hashim, "Seedless growth of zinc oxide flowershaped structures on multilayer graphene by electrochemical deposition," Nanoscale Research Letters, vol. 9, no. 1, pp. 1-9, 2014.

[70] Ö. Guler, S. H. Guler, F. Yo et al., "Electrical and optical properties of carbon nanotube hybrid zinc oxide nanocomposites prepared by ball mill technique," Fullerenes Nanotubes and Carbon Nanostructures, vol. 23, no. 10, pp. 865-869, 2015.

[71] Y. Zhang, X. Sun, L. Pan et al., "Carbon nanotube-ZnO nanocomposite electrodes for supercapacitors," Solid State Ionics, vol. 180, no. 32-35, pp. 1525-1528, 2009.

[72] X.-B. Yan, B.-K. Tay, Y. Yang, and W. Y. K. Po, "Fabrication of three-dimensional $\mathrm{ZnO}$-Carbon Nanotube (CNT) hybrids using self-assembled CNT micropatterns as framework," The Journal of Physical Chemistry C, vol. 111, no. 46, pp. 17254-17259, 2007.

[73] R. Paul, P. Kumbhakar, and A. K. Mitra, "Bluegreen luminescence by SWCNT/ZnO hybrid nanostructure synthesized by a simple chemical route," Physica E: Low-Dimensional Systems and Nanostructures, vol. 43, no. 1, pp. 279-284, 2010.

[74] T. A. Saleh, M. A. Gondal, and Q. A. Drmosh, "Preparation of a MWCNT/ZnO nanocomposite and its photocatalytic activity for the removal of cyanide from water using a laser," Nanotechnology, vol. 21, no. 49, Article ID 495705, 2010.

[75] B. Aïssa, C. Fauteux, M. A. E. Khakani, and D. Therriault, "Structural and photoluminescence properties of laser processed $\mathrm{ZnO} /$ carbon nanotube nanohybrids," Journal of Materials Research, vol. 24, no. 11, pp. 3313-3320, 2009.

[76] S. S. S. A. Aziz, N. I. Harun, N. Salleh et al., "Mechanochemical synthesis of CNT/ZnO hybrid materials," Materials Science Forum, vol. 846, pp. 479-483, 2016.

[77] B. K. Gupta, V. Grover, G. Gupta, and V. Shanker, "Highly efficient luminescence from hybrid structures of $\mathrm{ZnO} /$ multiwalled carbon nanotubes for high performance display applications," Nanotechnology, vol. 21, no. 47, Article ID 475701, 2010.

[78] X. L. Li, C. Li, Y. Zhang, D. P. Chu, W. I. Milne, and H. J. Fan, "Atomic layer deposition of $\mathrm{ZnO}$ on multi-walled carbon nanotubes and its use for synthesis of CNT-ZnO heterostructures," Nanoscale Research Letters, vol. 5, no. 11, pp. 1836-1840, 2010.

[79] D. S. Kim, S.-M. Lee, R. Scholz et al., "Synthesis and optical properties of $\mathrm{ZnO}$ and carbon nanotube based coaxial heterostructures," Applied Physics Letters, vol. 93, no. 10, Article ID 103108, 2008.

[80] C. H. Wang, A. S. W. Wong, and G. W. Ho, "Facile solution route to vertically aligned, selective growth of $\mathrm{ZnO}$ nanostructure arrays," Langmuir, vol. 23, no. 24, pp. 11960-11963, 2007.

[81] Z. L. Wang, "Zinc oxide nanostructures: growth, properties and applications," Journal of Physics: Condensed Matter, vol. 16, no. 25, pp. R829-R858, 2004. 
[82] A. B. Djurišić, Y. H. Leung, K. H. Tam et al., "Green, yellow, and orange defect emission from $\mathrm{ZnO}$ nanostructures: influence of excitation wavelength," Applied Physics Letters, vol. 88, no. 10, Article ID 103107, 2006.

[83] E. Rauwel, A. Galeckas, P. Rauwel et al., "Metal oxide nanoparticles embedded in rare-earth matrix for low temperature thermal imaging applications," Materials Research Express, vol. 3, no. 5, Article ID 055010, 2016.

[84] L. Wu, Y. Wu, X. Pan, and F. Kong, "Synthesis of $\mathrm{ZnO}$ nanorod and the annealing effect on its photoluminescence property," Optical Materials, vol. 28, no. 4, pp. 418-422, 2006.

[85] L. Dai, X. L. Chen, W. J. Wang, T. Zhou, and B. Q. Hu, "Growth and luminescence characterization of large-scale zinc oxide nanowires," Journal of Physics: Condensed Matter, vol. 15, no. 13, pp. 2221-2226, 2003.

[86] A. El Hichou, M. Addou, J. Ebothé, and M. Troyon, "Influence of deposition temperature (Ts), air flow rate (f) and precursors on cathodoluminescence properties of $\mathrm{ZnO}$ thin films prepared by spray pyrolysis," Journal of Luminescence, vol. 113, no. 3-4, pp. 183-190, 2005.

[87] X. Sun, Z. Liu, K. Welsher et al., "Nano-graphene oxide for cellular imaging and drug delivery," Nano Research, vol. 1, no. 3, pp. 203-212, 2008.

[88] Z. Luo, P. M. Vora, E. J. Mele, A. T. C. Johnson, and J. M. Kikkawa, "Photoluminescence and band gap modulation in graphene oxide," Applied Physics Letters, vol. 94, no. 11, Article ID 111909, 2009.

[89] M. Khenfouch, M. Baitoul, and M. Maaza, "White photoluminescence from a grown $\mathrm{ZnO}$ nanorods/graphene hybrid nanostructure," Optical Materials, vol. 34, no. 8, pp. 1320-1326, 2012.

[90] Z. H. Lim, Z. X. Chia, M. Kevin, A. S. W. Wong, and G. W. Ho, "A facile approach towards $\mathrm{ZnO}$ nanorods conductive textile for room temperature multifunctional sensors," Sensors and Actuators B: Chemical, vol. 151, no. 1, pp. 121-126, 2010.

[91] R. K. Biroju, P. K. Giri, S. Dhara, K. Imakita, and M. Fujii, "Graphene-assisted controlled growth of highly aligned $\mathrm{ZnO}$ nanorods and nanoribbons: growth mechanism and photoluminescence properties," ACS Applied Materials \& Interfaces, vol. 6, no. 1, pp. 377-387, 2014.

[92] G. Singh, A. Choudhary, D. Haranath et al., " $\mathrm{ZnO}$ decorated luminescent graphene as a potential gas sensor at room temperature," Carbon, vol. 50, no. 2, pp. 385-394, 2012.

[93] Z. Wu, Y. Shen, X. Li, Q. Yang, and S. Lin, "Green lightemitting diode based on graphene- $\mathrm{ZnO}$ nanowire van der Waals heterostructure," Frontiers of Optoelectronics, vol. 9, no. 1, pp. 87-92, 2016.

[94] F. Han, S. Yang, W. Jing et al., "Surface plasmon enhanced photoluminescence of $\mathrm{ZnO}$ nanorods by capping reduced graphene oxide sheets," Optics Express, vol. 22, no. 10, pp. 1143611445, 2014

[95] H. Zeng, Y. Cao, S. Xie et al., "Synthesis, optical and electrochemical properties of $\mathrm{ZnO}$ nanowires/graphene oxide heterostructures," Nanoscale Research Letters, vol. 8, article 133, 2013.

[96] C. Zhang, J. Zhang, Y. Su, M. Xu, Z. Yang, and Y. Zhang, “ZnO nanowire/reduced graphene oxide nanocomposites for significantly enhanced photocatalytic degradation of Rhodamine 6G," Physica E: Low-Dimensional Systems and Nanostructures, vol. 56, pp. 251-255, 2014.

[97] E. Lee, J.-Y. Kim, B. J. Kwon, E.-S. Jang, and S. J. An, "Vacancy filling effect of graphene on photoluminescence behavior of
ZnO/graphene nanocomposite," Physica Status Solidi (RRL)— Rapid Research Letters, vol. 8, no. 10, pp. 836-840, 2014.

[98] S. I. Weissman, "Intramolecular energy transfer the fluorescence of complexes of Europium," The Journal of Chemical Physics, vol. 10, no. 4, pp. 214-217, 1942.

[99] S. W. Hwang, D. H. Shin, C. O. Kim et al., "Plasmonenhanced ultraviolet photoluminescence from hybrid structures of graphene/ZnO films," Physical Review Letters, vol. 105, no. 12, Article ID 127403, 2010.

[100] S. Qu, X. Wang, Q. Lu, X. Liu, and L. Wang, "A biocompatible fluorescent ink based on water-soluble luminescent carbon nanodots," Angewandte Chemie - International Edition, vol. 51, no. 49, pp. 12215-12218, 2012.

[101] W. Wei, C. Xu, L. Wu, J. Wang, J. Ren, and X. Qu, "Nonenzymatic-browning-reaction: a versatile route for production of nitrogen-doped carbon dots with tunable multicolor luminescent display," Scientific Reports, vol. 4, article 3564, 2014.

[102] S. Qu, H. Chen, X. Zheng, J. Cao, and X. Liu, "Ratiometric fluorescent nanosensor based on water soluble carbon nanodots with multiple sensing capacities," Nanoscale, vol. 5, no. 12, pp. 5514-5518, 2013.

[103] D.-Y. Guo, C.-X. Shan, S.-N. Qu, and D.-Z. Shen, "Highly sensitive ultraviolet photodetectors fabricated from $\mathrm{ZnO}$ quantum dots/carbon nanodots hybrid films," Scientific Reports, vol. 4, article 7469, 2014

[104] L. He, S. Mei, Q. Chen et al., "Two-step synthesis of highly emissive $\mathrm{C} / \mathrm{ZnO}$ hybridized quantum dots with a broad visible photoluminescence," Applied Surface Science, vol. 364, pp. 710717, 2016.

[105] K. Suzuki, M. Takahashi, L. Malfatti, and P. Innocenzi, "Carbon dots in $\mathrm{ZnO}$ macroporous films with controlled photoluminescence through defects engineering," RSC Advances, vol. 6, no. 60, pp. 55393-55400, 2016.

[106] L. Tang, R. Ji, X. Li, K. S. Teng, and S. P. Lau, "Energy-level structure of nitrogen-doped graphene quantum dots," Journal of Materials Chemistry C, vol. 1, no. 32, pp. 4908-4915, 2013.

[107] Y. H. Lu, Z. X. Hong, Y. P. Feng, and S. P. Russo, "Roles of carbon in light emission of ZnO," Applied Physics Letters, vol. 96, no. 9, Article ID 091914, 2010.

[108] Y. Hu and H.-J. Chen, "Enhancement of green luminescence of $\mathrm{ZnO}$ powders by annealing with carbon black," Materials Research Bulletin, vol. 43, no. 8-9, pp. 2153-2159, 2008.

[109] C. Jin, S. Lee, C.-W. Kim, S. Park, C. Lee, and D. Lee, "Comparison of photoluminescence of carbon nanotube/ $\mathrm{ZnO}$ nanostructures synthesized by gas- and solution-phase transport," Applied Physics A, vol. 118, no. 2, pp. 733-738, 2015.

[110] R. Zhang, L. Fan, Y. Fang, and S. Yang, "Electrochemical route to the preparation of highly dispersed composites of $\mathrm{ZnO} /$ carbon nanotubes with significantly enhanced electrochemiluminescence from ZnO," Journal of Materials Chemistry, vol. 18, no. 41, pp. 4964-4970, 2008.

[111] Y. Zhu, X. Zhang, R. Li, and Q. Li, "Planar-defect-rich zinc oxide nanoparticles assembled on carbon nanotube films as ultraviolet emitters and photocatalysts," Scientific Reports, vol. 4, article 4728, 2014

[112] K. Vanheusden, W. L. Warren, C. H. Seager, D. R. Tallant, J. A. Voigt, and B. E. Gnade, "Mechanisms behind green photoluminescence in $\mathrm{ZnO}$ phosphor powders," Journal of Applied Physics, vol. 79, no. 10, pp. 7983-7990, 1996.

[113] Y. H. Ko, M. S. Kim, and J. S. Yu, "Structural and optical properties of zno nanorods by electrochemical growth 
using multi-walled carbon nanotubecomposed seed layers," Nanoscale Research Letters, vol. 7, article 13, 2012.

[114] A.-A. E. Mel, M. Buffière, C. P. Ewels et al., "Zn based nanoparticle-carbon nanotube hybrid materials: interaction and charge transfer," Carbon, vol. 66, pp. 442-449, 2014.

[115] G.-L. Chai, C.-S. Lin, and W.-D. Cheng, "First-principles study of $\mathrm{ZnO}$ cluster-decorated carbon nanotubes," Nanotechnology, vol. 22, no. 44, Article ID 445705, 2011. 

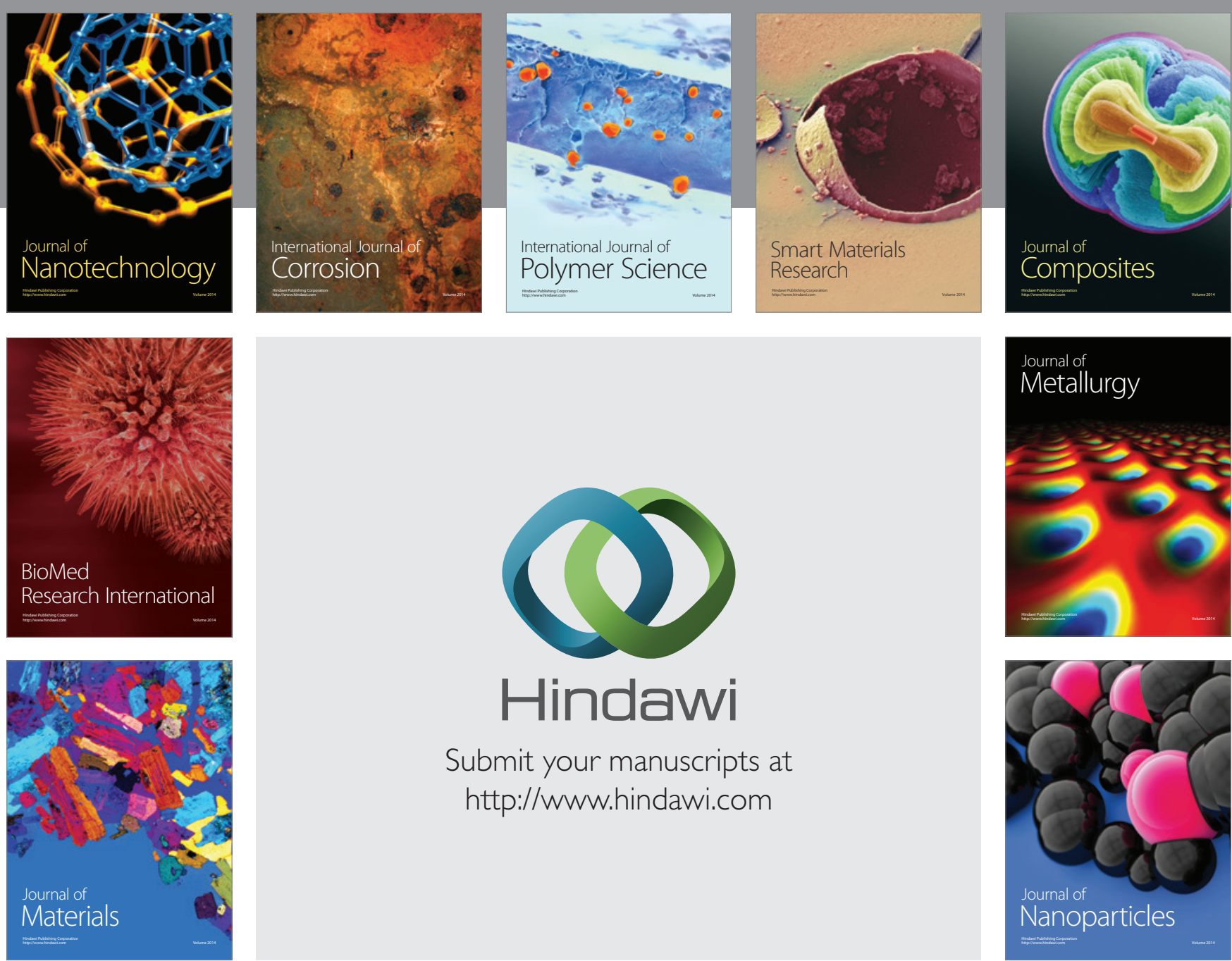

\section{Hindawi}

Submit your manuscripts at

http://www.hindawi.com

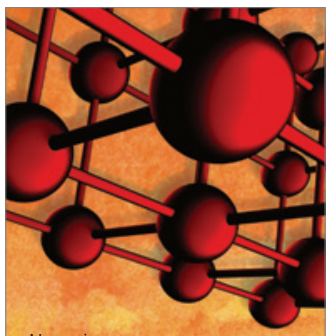

Materials Science and Engineering
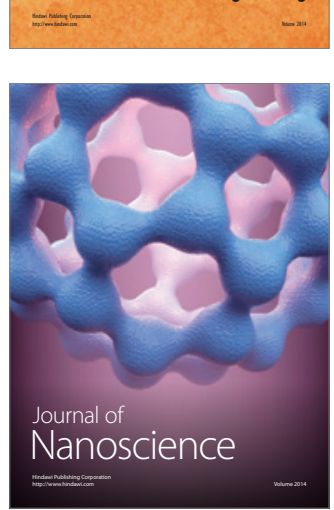
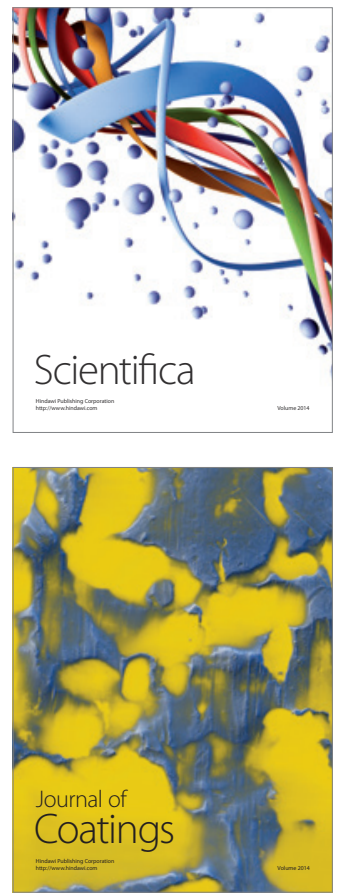
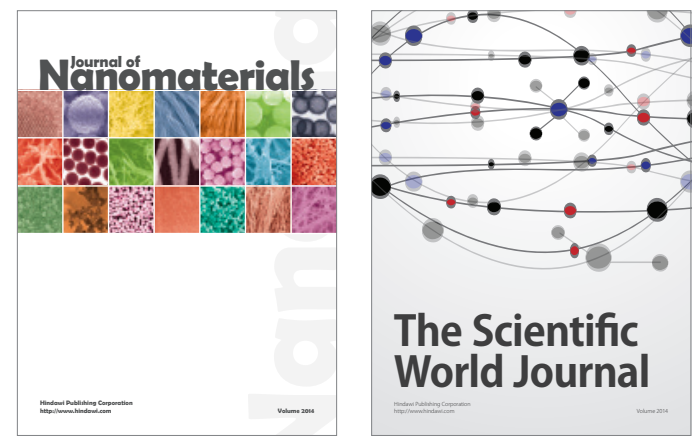

The Scientific World Journal
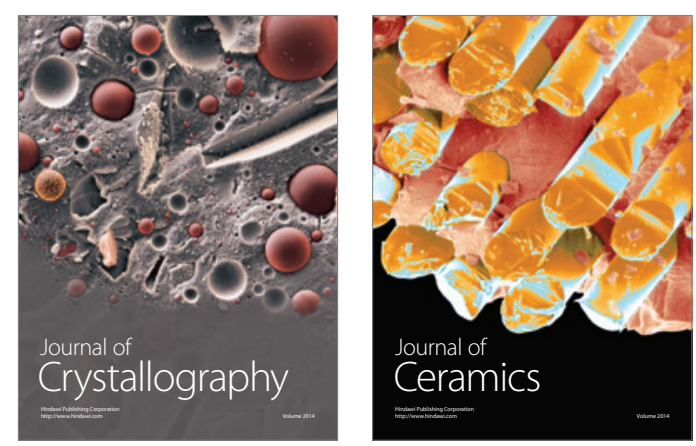
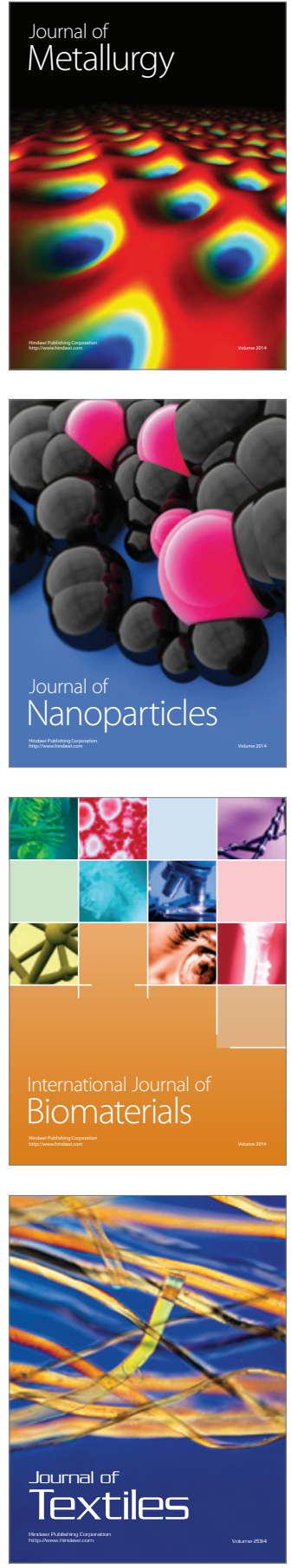